\title{
Effect of fragmentation, habitat loss and within-patch habitat characteristics on ant assemblages in semi-arid woodlands of eastern Australia
}

\author{
Valerie J. Debuse $\cdot$ Judith King $\cdot$ \\ Alan P. N. House
}

Received: 27 June 2006/ Accepted: 21 November 2006/Published online: 28 February 2007

(C) Retained by the State of Queensland 2007

\begin{abstract}
The reliability of ants as bioindicators of ecosystem condition is dependent on the consistency of their response to localised habitat characteristics, which may be modified by larger-scale effects of habitat fragmentation and loss. We assessed the relative contribution of habitat fragmentation, habitat loss and within-patch habitat characteristics in determining ant assemblages in semi-arid woodland in Queensland, Australia. Species and functional group abundance were recorded using pitfall traps across 20 woodland
\end{abstract}

The State of Queensland's right to retain a non-exclusive, royalty free license in and to any copyright is acknowledged.

V. J. Debuse $(\bowtie)$

Department of Primary Industries and Fisheries, Horticulture and Forestry Science, Locked Bag 16, Gympie, QLD 4570, Australia

e-mail: valerie.debuse@dpi.qld.gov.au

V. J. Debuse

The Centre for Innovative Conservation Strategies, Griffith University, PMB 50, Gold Coast MC, QLD 9726, Australia

\section{J. King}

Department of Primary Industries and Fisheries, Horticulture and Forestry Science, 80, Meiers Road, Indooroopilly, QLD 4068, Australia

\author{
A. P. N.House \\ CSIRO Sustainable Ecosystems, 306, Carmody Road, \\ St Lucia, QLD 4067, Australia
}

patches in landscapes that exhibited a range of fragmentation states. Of fragmentation measures, changes in patch area and patch edge contrast exerted the greatest influence on species assemblages, after accounting for differences in habitat loss. However, $35 \%$ of fragmentation effects on species were confounded by the effects of habitat characteristics and habitat loss. Within-patch habitat characteristics explained more than twice the amount of species variation attributable to fragmentation and four times the variation explained by habitat loss. The study indicates that withinpatch habitat characteristics are the predominant drivers of ant composition. We suggest that caution should be exercised in interpreting the independent effects of habitat fragmentation and loss on ant assemblages without jointly considering localised habitat attributes and associated joint effects.

Keywords Landscape - Functional groups · Variance partitioning

\section{Introduction}

Habitat fragmentation and loss are critical processes influencing species distribution across a landscape. The commonly recognised consequences of increased fragmentation on landscape structure are increased isolation among similar patch types and reduction in patch size 
(MacArthur and Wilson 1967; Andrén 1994). Classically, patch area reduction and increased isolation should have detrimental effects on species abundance and richness since patches are less likely to be colonised after a local extinction (Brown and Kodric-Brown 1977; Hanski 1999), and should hold smaller populations that are more vulnerable to environmental and demographic stochasticity (Fahrig 1997; Foley 1997). These deleterious effects may be exacerbated by an associated increase in edge environments that influences species movement patterns across patch boundaries (Bhar and Fahrig 1998).

While patch area and isolation are the most commonly tested measures of fragmentation (Laurance and Bierregaard 1997; Fahrig 2003), they are unable to consistently predict species richness patterns in manipulative fragmentation studies (Debinski and Holt 2000). The conceptual shift from island biogeography theory (MacArthur and Wilson 1967) to models that consider the landscape matrix to be heterogeneous and not necessarily hostile to native species (e.g. habitat variegation concept, McIntyre and Barrett 1992), has led to alternative landscape features such as landscape heterogeneity and contrast between adjacent land types being increasingly incorporated into fragmentation studies (McGarigal and Marks 1995; Wiens 1997; Fahrig 2003). Such features are important drivers of population dynamics in some species (Niemelä 2001; Jules and Shahani 2003), which may override the effects of area and isolation. Inconsistent effects of area and isolation among fragmentation studies also result from confounding effects of habitat loss (Andrén 1994; Fahrig 2003); once the effects of fragmentation and loss are separated, habitat loss may exert a stronger and, in some cases, opposite effect on species dynamics to fragmentation (Fahrig 2003). Differences in patch isolation have been shown to reflect changes in habitat loss more closely than changes in fragmentation per se (defined as the breaking apart of habitat independent of habitat loss; Fahrig 2003). Thus, it is important to account for the relationship between the amount of habitat in the landscape and fragmentation characteristics to ensure that habitat loss impacts are not misinterpreted as fragmentation effects (Fahrig 2003).

The consistency of species responses to fragmentation may be further modified by withinpatch habitat conditions. Indeed, the degree of natural and anthropogenic disturbance may influence species dynamics to an equal or greater extent than larger scale landscape structure (Ross et al. 2002; Jellinek et al. 2004; Pharo et al. 2004). Disturbances such as grazing and fire in woodland habitats have major impacts on vegetation structure (Russell-Smith and Stanton 2002; Bowman and Prior 2004), plant cover (Hobbs 2001), soil nutrition (Guinto et al. 1999) and soil-water infiltration (Hobbs 2001), thereby altering habitat suitability for a range of fauna (Martin and Green 2002). Localised habitat effects should be particularly influential on populations of smaller, less vagile species such as many ground-dwelling insects, for which dispersal distances are too low for larger-scale landscape structure to exert a strong influence (Abensperg-Traun et al. 1996).

Ants are the most commonly used insect bioindicators of habitat condition in Australia, owing to their abundance, diversity, sensitivity to disturbance and close relationship with soil structure and nutrient cycling (Hoffmann and Andersen 2003; Andersen and Majer 2004). Functional groupings of ants that are based primarily on competitive dynamics and inter-taxa differences in habitat requirements (Andersen 1995) have been applied successfully to assess post-disturbance recovery from fire, mining and grazing (Vanderwoude et al. 1997; Hoffmann and Andersen 2003). However, the importance of habitat differences as determinants of ant composition, and thus the reliability of ants as habitat bioindicators, has not been quantified against the independent (pure) effects of habitat loss and fragmentation and joint (confounded) effects that are simultaneously explained by aspects of habitat fragmentation, loss and within-patch characteristics (Cushman and McGarigal 2002). To determine this, we devised a simple conceptual model that emphasised three major influences (habitat fragmentation, habitat loss, withinpatch habitat characteristics) and associated joint effects on ant species assemblages in fragmented landscapes (Fig. 1). 


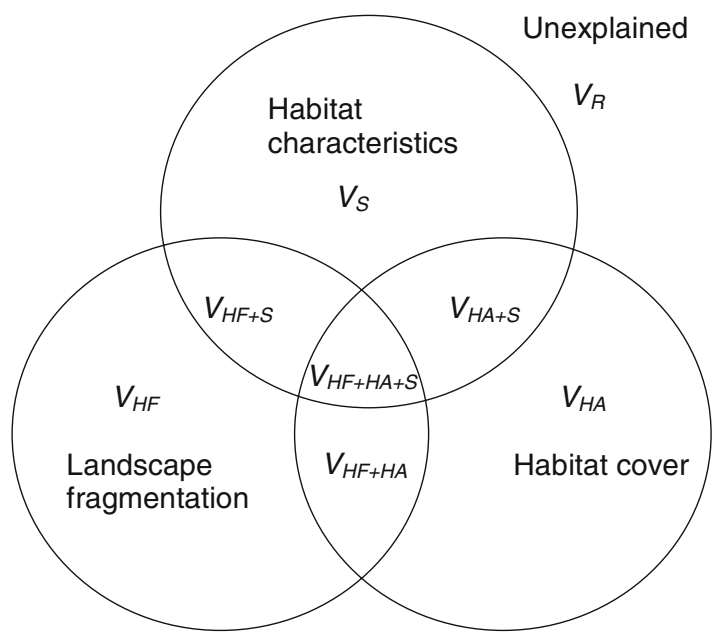

Fig. 1 Conceptual model of major determinants that influence ant assemblages in fragmented landscapes divided into the independent effects of landscape fragmentation $\left(V_{\mathrm{HF}}\right)$, habitat cover $\left(V_{\mathrm{HA}}\right)$ and within-patch habitat characteristics $\left(V_{\mathrm{S}}\right)$, corresponding joint effects $\left(V_{\mathrm{HF}+\mathrm{HA}}, V_{\mathrm{HF}+\mathrm{S}}, V_{\mathrm{HA}+\mathrm{S}}, V_{\mathrm{HF}+\mathrm{HA}+\mathrm{S}}\right)$ and unexplained effects $\left(V_{\mathrm{R}}\right)$

We formulated two hypotheses. First, we predicted that differences in habitat loss would account for a greater proportion of variation in ant species assemblages among patches than the effects of habitat fragmentation. This hypothesis tested Fahrig's (2003) theory that habitat loss exerts a greater influence on species dynamics than fragmentation once both effects are separated. Second, we predicted that ant composition should be more strongly influenced by within-patch habitat characteristics than by fragmentation or habitat loss. In particular, we would expect those habitat characteristics that increase or reduce low temperature stress, where stress is defined as any factor limiting productivity (Andersen 1995), would show strong correlations to ant species abundance. This prediction is based on findings from other invertebrate studies in eucalypt woodlands (Abensperg-Traun et al. 1996; Hoffmann and Andersen 2003) and reflects the importance of temperature as a key determinant of ant community structure (Andersen 1995).

We tested our predictions in semi-arid poplar box (Eucalyptus populnea) woodlands, a major vegetation type in the Brigalow Belt South bioregion in southern Queensland, Australia (Sattler and Williams 1999). The 27.2 million ha bioregion has been extensively modified for agricultural development since approximately 1850. In the western region, where we conducted our study, approximately $36 \%$ of native vegetation remained in 2003 (Queensland Department of Natural Resources and Water 2003). Vegetation clearing has had a major impact on distribution and abundance of poplar box woodlands, and the condition of remaining poplar box remnants is largely unknown. By understanding the relative importance of habitat loss, fragmentation and within-patch habitat characteristics, we can determine whether ants are viable bioindicators of poplar box woodland condition, or whether ant communities are being driven more strongly by landscape structure.

\section{Methods}

The study was conducted from March-August 2003 in southern Queensland, Australia. Ants were sampled in poplar box remnants across an area of approximately 4.5 million ha, extending west from Miles (150.11 E 26.39 S) to Morven (147.6 E 26.25 S) and north from Surat (149.4 E $27.9 \mathrm{~S})$ to Injune $(148.33 \mathrm{E} 25.50 \mathrm{~S})$. Using 1:100,000 ecosystem mapping, 20 patches were selected that were mapped either as poplar box woodland on alluvial plains or as poplar box dominant or co-dominant ecosystems. Within the bioregion, all patches were located within one sub-region to reduce biogeographical variability and represented a broad range of fragmentation states, particularly maximising differences in poplar box patch area, degree of contrast between patches (patch edge contrast) and isolation between poplar box patches (Euclidean nearest neighbour). One $100 \times 10 \mathrm{~m}$ plot was located as far as possible from patch boundaries to reduce edge effects and where access was allowed by the landholder. Plots were also sited in positions to minimise the number of idiosyncratic landscape features (e.g. dams).

\section{Environmental predictors}

Three sets of environmental predictors that we anticipated may influence ant assemblages were 
derived: (1) fragmentation characteristics (2) habitat loss and (3) within-patch habitat characteristics. Fragmentation measures (Table 1) were calculated for a 500 ha landscape surrounding each plot, which represented a circular area of $1.3 \mathrm{~km}$ radius centred on each plot. The $1.3 \mathrm{~km}$ radius landscape was an appropriate scale for dominant ant species such as Iridomyrmex spp. (Greenslade and Halliday 1983; Hölldobler and Wilson 1990), by representing a scale larger than its home range but smaller than its regional distribution. However, some poplar box patches were isolated such that they were the only one within the $1.3 \mathrm{~km}$ radius; thus, Euclidean nearest neighbour distance metrics were calculated within a $5 \mathrm{~km}$ radius (8,000 ha). Habitat loss (also referred to as habitat cover) was measured as total area of native vegetation cover remaining in each 500 ha landscape in 2003 (Table 1).

Eight measures of fragmentation were calculated using FRAGSTATS 3.0 (McGarigal and Marks 1995; Table 1). These metrics described individual poplar box patch features (patch area, patch shape, land use contrast of adjacent patches), characteristics of all poplar box patches in each 500 ha landscape (disjunct core area density, mean nearest neighbour distance, density of edge habitats weighted by land type contrast, interspersion and juxtaposition of poplar box patches) and characteristics of all patch types in the 500 ha landscape (land type diversity). Weightings were assigned to each land type according to the similarity to poplar box; smaller values were assigned to land types that showed greater similarity to poplar box (e.g. other native vegetation). Core areas were defined as poplar box patch areas excluding an edge width of $100 \mathrm{~m}$. The selected metrics did not exhibit unpredictable or inconsistent responses to changes in grain size (e.g. patch richness, patch richness density, Shannon's diversity index) or extent (e.g. patch density, edge density, landscape shape index, mean shape index; $\mathrm{Wu}$ et al. 2002) and did not include metrics that provide unreliable estimates where the frequency of relevant patch types in the landscape was low (e.g. double log fractal dimension; McGarigal and Marks 1995).

The eight selected fragmentation metrics and one measure of habitat cover were combined with seven habitat variables representing annual rainfall, soil properties, vegetation attributes and patch disturbance (Table 1). Percentage soil clay content was assessed from the soil particle size distribution, and measured using $20 \times 10-\mathrm{cm}$ deep soil cores per patch, which were bulked together and sub-sampled. Samples were airdried, passed through a sieve to remove roots and rocks and ground to $<2 \mathrm{~mm}$ for particle size analysis. The percentages of coarse sand $(0.2-2.0 \mathrm{~mm})$, fine sand $(0.02-0.2 \mathrm{~mm})$, silt $(0.002-0.02 \mathrm{~mm})$ and clay particles $(<0.002 \mathrm{~mm})$ were separated gravimetrically and assessed using a hydrometer. Projected foliage cover was measured using a gimbal ring sighting tube at $1 \mathrm{~m}$ intervals along a $100 \mathrm{~m}$ transect. Annual rainfall data was calculated for each plot from Bureau of Meteorology observational data over 35 years (1968-2003), which were spatially interpolated to assess rainfall at plots sited between stations. The severity of patch disturbance from a range of sources (Table 1) was measured on a scale of 0 (no evidence of disturbance) to 5 (severe disturbance) for each disturbance type, and was determined by on-site visual assessments and information from land managers. Given that ants often respond to low temperature stress at ground level (Hoffmann and Andersen 2003; Andersen 1995), sources of disturbance were collated into two groups: those associated with increasing plant cover (weed occurrence), and hence decreased ground-level insolation, and those associated with decreasing plant cover (all others; Table 1). Scores were then summed to produce a disturbance index for each group. Density of shrublayer (mid-stratum) vegetation 1-4 $\mathrm{m}$ in height and/or less than $5 \mathrm{~cm}$ diameter at breast height was measured within one $50 \times 10 \mathrm{~m}$ subplot per plot.

\section{Ant sampling}

Each $100 \times 10 \mathrm{~m}$ sampling plot $(n=20)$ contained two grids of nine pitfall traps that were spaced $5 \mathrm{~m}$ apart in a $3 \times 3$ configuration. Each plot was sampled in March and August 2003 to incorporate seasonal variation in community structure. Individual traps consisted of $120 \mathrm{ml}$ jars (40 mm diameter) containing $60 \mathrm{ml}$ of $70 \%$ 


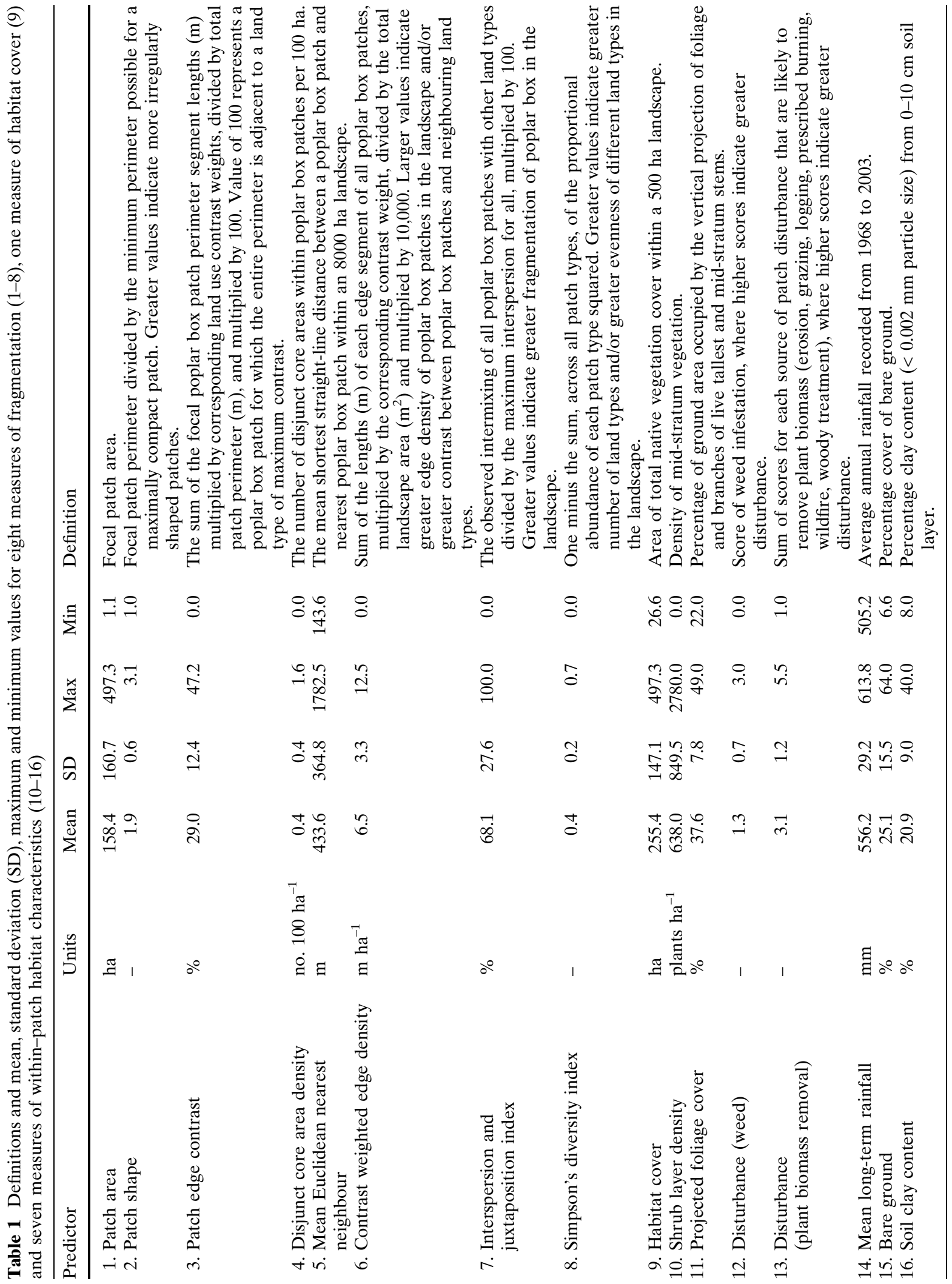


ethyl alcohol and a few drops of glycerol to reduce evaporation. The traps were sunk into the ground so that the jar rims were flush with the soil surface and disturbed soil and litter were replaced around the mouth of the trap after insertion. Traps were opened for a 4-day period, following sampling methods previously adopted in Australia and South Africa (Jackson and Fox 1996; Samways et al. 1997; Vanderwoude 1999). Heavy rain and hot sun during sampling periods severely affected trap contents in six plots, resulting in traps being filled with water and/or silt and drying out due to excessive evaporation, respectively. Prior to sealing, the contents of rain-affected traps were allowed to settle, excess rainwater was decanted off and replaced by $70 \%$ ethyl alcohol or methylated spirits. Where possible, we identified ants to species/morphospecies level using a combination of keys, determined specimens and expert assistance, and assigned them to the nine functional groups (Dominant Dolichoderinae, Subordinate Camponotini, Hot Climate Specialists, Cold Climate Specialists, Tropical Climate Specialists, Cryptic Species, Opportunists, Generalized Myrmicinae, Specialist Predators). We refer to morphospecies as "species" throughout this paper for simplicity. Species prevalence in each trap was recorded using an abundance scale ( $1=1$ individual, $2=2-5$ individuals, $3=6-20$ individuals, $4=21-50$ individuals and $5=50+$ individuals).

\section{Analysis}

After combining sampling months, species abundance ratings were averaged over all traps at each plot rather than summed, to reduce the impact of differences in the numbers of traps that were rain or sun-affected among plots (see previous paragraph). Given the logarithmic nature of the abundance scale, further transformation of species data was not required to meet the assumptions of normality prior to multivariate analyses. A species accumulation curve on combined sampling month data (maximum permutations = 5000) determined the efficiency of the sampling methods to capture total species richness. Multivariate analyses were carried out on species that were present at five sites or greater $(n=31)$ to further improve statistical robustness.

We used a series of partial redundancy analysis (RDA) runs to partition among-patch variation in species assemblages among landscape fragmentation, habitat cover and within-patch habitat characteristics. Prior to analysis, preliminary detrended correspondence analysis (DCA) was undertaken to confirm that species responses to environmental predictors were more linear than Gaussian (<3SD; ter Braak and Šmilauer 2002). The RDA also accounts for potential confounded effects between sets of environmental predictors assuming linear inter-relationships. However, one of the eight fragmentation variables, diversity of land types, showed a strong quadratic response to habitat cover. Thus, we derived residuals from linear and quadratic regressions between fragmentation variables and habitat cover, and used the residuals as fragmentation measures. Where non-linear relationships are present, this approach provides a more accurate method of separating the effects of fragmentation and habitat cover than using covariates, while still being able to calculate the independent effects of both factors. Nevertheless, the joint effects of habitat cover and fragmentation $\left(V_{\mathrm{HF}+\mathrm{HA}}\right.$; Fig. 1$)$ are negligible using this method and thus not interpretable. Mean Euclidean nearest neighbour and shrublayer density (Table 1) were transformed prior to regression analysis to meet the assumptions of normality and variance homogeneity. Collinearity was checked using correlation analysis on fragmentation and habitat variables, but there were no highly correlated relationships among variables (fragmentation: $r<0.66$; habitat: $r<0.44)$.

Based on Borcard et al. (1992), we calculated eight individual variance components. These were the proportion of variance attributable to: independent effects of habitat fragmentation $\left(V_{\mathrm{HF}}\right)$, habitat cover $\left(V_{\mathrm{HA}}\right)$ and within-patch habitat characteristics $\left(V_{\mathrm{S}}\right)$; joint effects of fragmentation and habitat cover $\left(V_{\mathrm{HF}+\mathrm{HA}}\right)$, fragmentation and within-patch habitat characteristics $\left(V_{\mathrm{HF}+\mathrm{S}}\right)$, habitat cover and within-patch habitat characteristics $\left(V_{\mathrm{HA}+\mathrm{S}}\right)$ and fragmentation, habitat cover and within-patch habitat characteristics $\left(V_{\mathrm{HF}+\mathrm{HA}+\mathrm{S}}\right)$; and none of the above (residual variation; $V_{\mathrm{R}}$ ). 
The eight variance components were derived from the proportion of total variance $\left(c e_{x}\right)$ explained by each of a series of RDA runs. Firstly, two RDA runs selected fragmentation and within-patch habitat measures that significantly contributed to explained variation $\left(c e_{1}, c e_{2}\right)$. To derive these, we assigned eight fragmentation residuals (first RDA) or seven within-patch habitat characteristics (second RDA) as independent variables. A forward selection procedure then excluded variables that did not significantly contribute to explained variation in each run. We tested significance at a $5 \%$ level $(P \leq 0.05)$, which was assessed by Monte Carlo permutation tests $(n=5000)$ that do not require multivariate normality (Manly 1991). An RDA run to select significant measures of habitat cover was unnecessary, since habitat cover was represented by one variable. Secondly, we calculated $V_{\mathrm{HF}}, V_{\mathrm{HA}}$ and $V_{\mathrm{S}}$ from three additional RDA runs. The third, fourth and fifth RDA runs assigned significant fragmentation measures, within-patch habitat variables and habitat cover as independent variables, respectively, while treating significant variables from the other two groups as covariates. For example, independent fragmentation effects $\left(V_{\mathrm{HF}}\right)$ were calculated by assigning significant fragmentation measures as independent variables and significant within-patch habitat characteristics and habitat cover as covariates.

Thirdly, we undertook a further three RDA runs to calculate joint effects of significant variables from any two of the three groups of environmental predictors $\left(V_{\mathrm{HF}+\mathrm{HA}}, V_{\mathrm{HF}+\mathrm{S}}\right.$, $\left.V_{\mathrm{HA}+\mathrm{S}}\right)$. The sixth RDA run allocated significant fragmentation variables and habitat cover as independent variables, and treated significant within-patch habitat characteristics as covariates. The proportion of variance derived from the RDA $\left(c e_{3}\right)$ represented the proportion $V_{\mathrm{HF}}+$ $V_{\mathrm{HA}}+V_{\mathrm{HF}+\mathrm{HA}}$, from which the variation component of joint effects of fragmentation and habitat cover $\left(V_{\mathrm{HF}+\mathrm{HA}}\right)$ was derived by:

$V_{\mathrm{HF}+\mathrm{HA}}=c e_{3}-\left(V_{\mathrm{HF}}+V_{\mathrm{HA}}\right)$

Using the same approach, the seventh RDA run assigned significant fragmentation measures and within-patch habitat characteristics as independent variables, while controlling for habitat cover, to produce the proportion $c e_{4}$ $\left(V_{\mathrm{HF}}+V_{\mathrm{S}}+V_{\mathrm{HF}+\mathrm{S}}\right)$. The variation component of joint effects of fragmentation and within-patch habitat was calculated as:

$V_{\mathrm{HF}+\mathrm{S}}=c e_{4}-\left(V_{\mathrm{HF}}+V_{\mathrm{S}}\right)$

Joint effects of habitat cover and within-patch habitat were calculated by an eighth RDA in the same fashion $\left(\mathrm{ce}_{5}\right)$, and were derived by:

$V_{\mathrm{HA}+\mathrm{S}}=c e_{5}-\left(V_{\mathrm{HA}}+V_{\mathrm{S}}\right)$

From results of previous RDA runs, we then calculated the joint effects of the three sets of variables $\left(V_{\mathrm{HF}+\mathrm{HA}+\mathrm{S}}\right)$ using the following equation:

$V_{\mathrm{HF}+\mathrm{HA}+\mathrm{S}}=\left(c e_{1}-V_{\mathrm{HF}}\right)-V_{\mathrm{HF}+\mathrm{S}}-V_{\mathrm{HF}+\mathrm{HA}}$

Finally, selected measures of fragmentation, habitat cover and within-habitat characteristics were assigned as independent variables in a ninth RDA run that determined total variation explained by fragmentation, loss and within-patch habitat effects. $V_{\mathrm{R}}$ was calculated as one minus the sum of all other variance components. For each RDA run, the significance of the sum of all canonical variates (trace) was calculated using a Monte Carlo permutation test $(n=5000)$. This statistical approach was also used to examine variation in ant functional group assemblages but showed qualitatively similar results to the species analysis.

\section{Results}

A total of 116 ant species from 26 genera was sampled in March and August 2003 (Appendix 1). Average species richness per plot was 21 after pooling both months, and genus and species richness tended to be greater in March than in August. The lack of asymptote in the species accumulation curve (Fig. 2) suggests that the sampling methodology did not capture total species richness across the study area.

Patch area was the only significant measure of fragmentation that explained variation in ant species assemblages across patches, after account- 


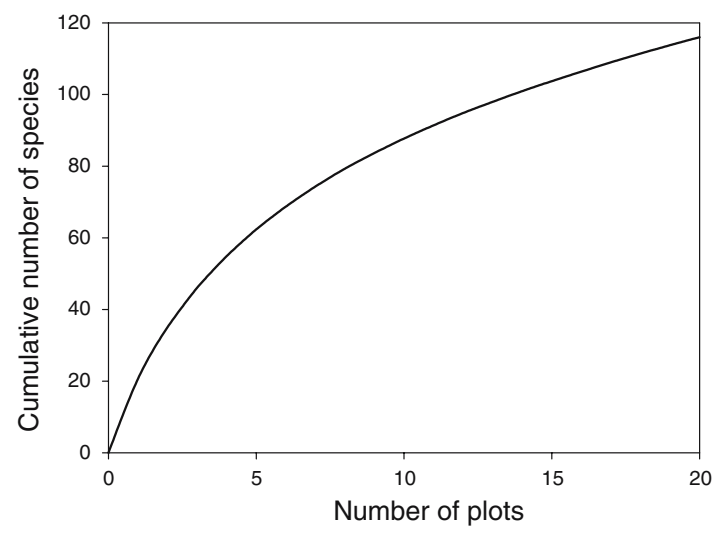

Fig. 2 Species accumulation curve showing cumulative number of ant species sampled across 20 plots for March and August combined

ing for habitat cover (Table 2). There was also a tendency for the degree of edge contrast of the neighbouring patch to be related to variation in ant species assemblages (Table 2). There were three significant within-patch habitat condition predictors: percentage of clay content in the soil, average annual precipitation for each patch from 1968-2003 and habitat disturbance severity from erosion, grazing, tree and shrub removal, prescribed burning and wildfire. Variation in species assemblages also tended to be influenced by bare ground cover (Table 2). Given high data variability and small sample size, we included the degree of edge contrast and bare ground cover in our final model. The six variables and habitat cover exhibited significant linear relationships with species assemblages (Monte Carlo permutation test: $F=1.5, P=0.001)$ and accounted for $46.1 \%$ of the total variation. Of this, the independent effects of within-patch habitat characteristics explained the largest proportion of variation, compared to the pure effects of fragmentation and habitat cover (Fig. 3a).

Joint effects of fragmentation and within-patch habitat characteristics and the combined effects of fragmentation, habitat cover and within-patch habitat characteristics accounted for most of the joint effects (Fig. 3a). Within-patch habitat characteristics and habitat cover confounded 35\%

Table 2 Nine RDA model runs on species assemblages, indicating covariates used, predictors selected by a forward stepwise procedure and total variance explained by each model run after accounting for the effects of the covariates (trace)

\begin{tabular}{|c|c|c|c|c|c|}
\hline \multirow[t]{2}{*}{ Model } & \multirow[t]{2}{*}{ Covariates } & \multicolumn{3}{|l|}{ Selected Predictors } & \multirow[t]{2}{*}{ Trace $^{b}$} \\
\hline & & Predictor & Eigenvalue $^{\mathrm{a}}$ & $P$-Value & \\
\hline \multirow[t]{2}{*}{ 1. Fragmentation } & & Patch area & 0.11 & 0.001 & \multirow[t]{2}{*}{0.182} \\
\hline & & Patch edge contrast & 0.07 & 0.066 & \\
\hline \multirow[t]{4}{*}{ 2. Within-patch habitat } & & $\%$ soil clay content & 0.09 & 0.009 & \multirow[t]{4}{*}{0.304} \\
\hline & & Rainfall & 0.08 & 0.037 & \\
\hline & & $\begin{array}{l}\text { Disturbance (plant } \\
\text { biomass removal) }\end{array}$ & 0.07 & 0.048 & \\
\hline & & $\%$ bare ground & 0.06 & 0.080 & \\
\hline 3. Fragmentation & $\begin{array}{l}\text { Within-patch habitat }+ \\
\text { habitat cover }\end{array}$ & & & & 0.118 \\
\hline 4. Habitat cover & $\begin{array}{l}\text { Fragmentation + within- } \\
\text { patch habitat }\end{array}$ & & & & 0.054 \\
\hline 5. Within-patch habitat & $\begin{array}{l}\text { Fragmentation + habitat } \\
\text { cover }\end{array}$ & & & & 0.245 \\
\hline $\begin{array}{l}\text { 6. Fragmentation }+ \text { within patch } \\
\text { habitat }\end{array}$ & Habitat cover & & & & 0.396 \\
\hline $\begin{array}{l}\text { 7. Habitat cover + within-patch } \\
\text { habitat }\end{array}$ & Fragmentation & & & & 0.309 \\
\hline 8. Fragmentation + habitat cover & Within-patch habitat & & & & 0.170 \\
\hline $\begin{array}{l}\text { 9. Fragmentation }+ \text { habitat cover }+ \\
\text { within-patch habitat }\end{array}$ & & & & & 0.461 \\
\hline
\end{tabular}

\footnotetext{
a Variance explained by each predictor

b Sum of all canonical eigenvalues, where 1.0 represents a model where all variance in the data is explained by selected predictors
} 

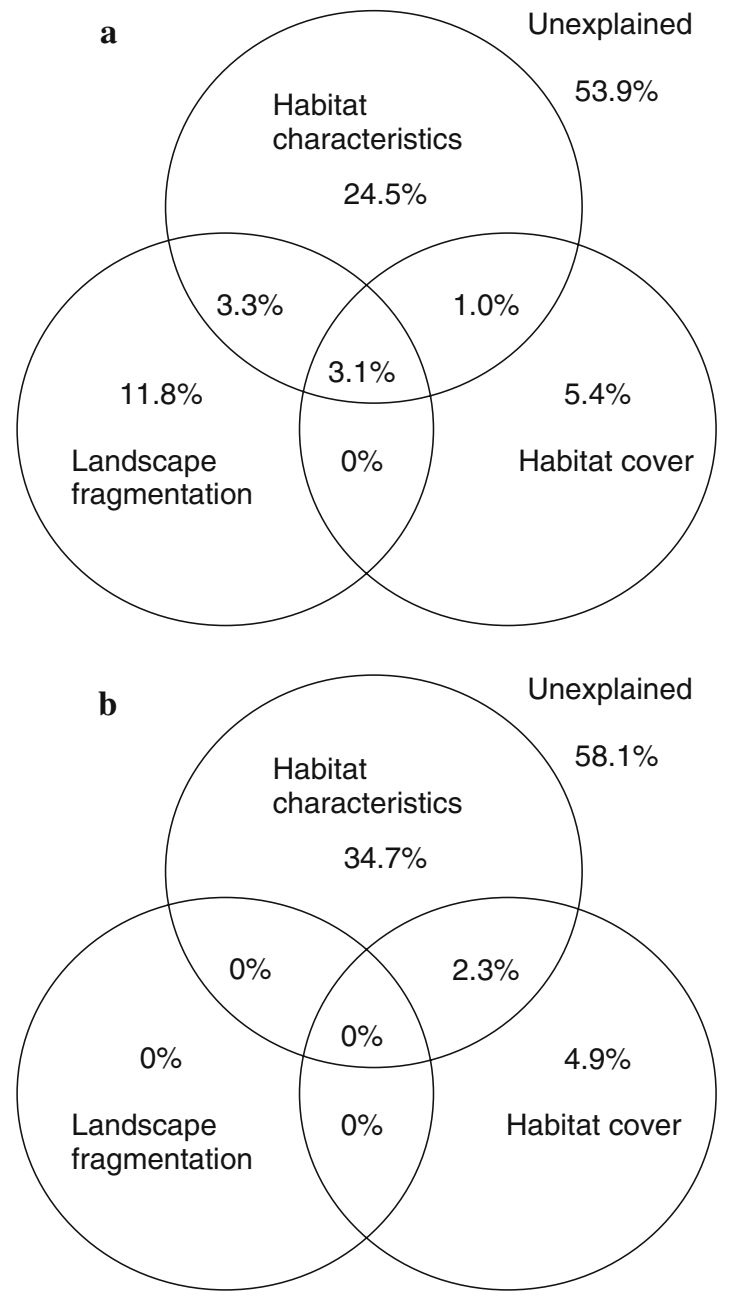

Fig. 3 Percentage variation explained of (a) ant species and (b) functional group assemblages among 20 patches as a result of variance partitioning. Variance components represent the independent effects of fragmentation $\left(V_{\mathrm{HF}}\right)$, habitat cover $\left(V_{\mathrm{HA}}\right)$ and within-patch habitat characteristics $\left(V_{\mathrm{S}}\right)$ and proportion of unexplained variation $\left(V_{\mathrm{R}}\right)$. $V_{\mathrm{HF}+\mathrm{HA}}, V_{\mathrm{HF}+\mathrm{S}}, V_{\mathrm{HA}+\mathrm{S}}, V_{\mathrm{HF}+\mathrm{HA}+\mathrm{S}}$ quantify the degree to which fragmentation, habitat loss and localised withinpatch habitat effects are confounded

$(6.4 / 18.2 \times 100)$ of the explanatory power of fragmentation, while $43 \%(4.1 / 9.5 \times 100)$ of the explanatory power of habitat cover was confounded by the effects of significant variables from the other two categories. In contrast, fragmentation and habitat cover confounded only $23 \%(7.4 / 31.9 \times 100)$ of the effects of withinpatch habitat characteristics on species assemblages. As expected from the use of residuals, the joint effects of fragmentation and habitat loss were negligible (Fig. 3a). When examining the corresponding responses on a functional group basis, there were qualitatively similar patterns, with the exception that fragmentation explained no variation in functional group assemblages across patches (Fig. 3b).

Clear responses of species to habitat and landscape variables were limited (Fig. 4). The preference of Monomorium 6 for sites with increased patch edge contrast indicates the broad habitat tolerance of Generalised Myrmicinae, and the positive relationship between abundance of Notoncus 7 (a Cold Climate Specialist) and habitat cover demonstrates a response to increased shadiness at landscape scale. Other clear responses were to local habitat conditions. A group of species-Monomorium 3, Pheidole 9 (both Generalised Myrmicinae) and Leptogenys 1 (Specialist Predator)—were associated with increasingly lighter soils, while Camponotus 11 (Subordinate Camponotini) and Crematogaster 3

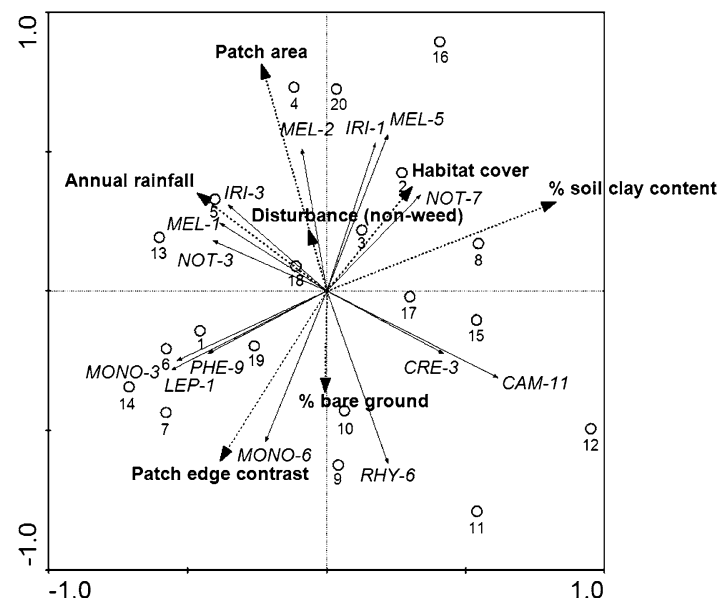

Fig. 4 Biplot based on redundancy analysis of species abundance using significant fragmentation measures, within-patch habitat variables and habitat cover; abbreviations are based on Appendix 1. Only species that show a minimum fit to the model of $20 \%$ or more are displayed for simplicity of presentation. Species arrows (solid) pointing in approximately the same direction as the environmental arrows (dotted) indicate a high positive correlation with that environmental predictor, arrows crossing at right angles indicate near-zero correlation and arrows pointing in opposite directions indicate high negative correlation. Longer environmental and species arrows indicate those metrics and species that provide more certainty about the predicted correlations. Site (patch) scores are indicated by numbered open circles 
(Generalised Myrmicinae) became more abundant as rainfall decreased. Species of Monomorium (Generalised Myrmicinae) and Rhytidoponera (Opportunist) were generally more abundant in sites where species of Iridomyrmex (Dominant Dolichoderinae) and Melophorus (Hot Climate Specialist) were less dominant.

\section{Discussion}

Our results demonstrated that habitat fragmentation metrics accounted for greater variation in species assemblages among patches than habitat cover. As expected, within-patch habitat characteristics were identified as stronger drivers of ant species assemblage differences among patches than habitat fragmentation or cover.

Our study suggests that within-patch habitat characteristics are the predominant influence on ant assemblages in Australian semi-arid woodlands. Differences in localised habitat characteristics explained over twice the amount of species variation across patches than did fragmentation measures. This difference, combined with our finding that over one-third of total fragmentation effects on species assemblages were confounded by the influence of within-patch habitat characteristics and habitat loss, suggests that fragmentation effects are considerably weaker than the impact of within-patch habitat. Thus, previously reported fragmentation effects on ant species (e.g. Suarez et al. 1998; Sobrinho et al. 2003; Schoereder et al. 2004) may largely be demonstrating independent and joint effects of within-patch habitat characteristics associated with fragmented states, rather than the sole effects of fragmentation per se. Indeed, our findings support Abensperg-Traun et al.'s (1996) conclusions that habitat characteristics were stronger predictors of arthropod communities than landscape structure in E. salubris woodlands in southwestern Australia.

Differences in local habitat structure and complexity are commonly associated with changes in animal communities (reviewed by Tews et al. 2004), including arthropod dynamics (Gardner et al. 1995; Hansen 2000; Lassau and Hochuli 2004). Features such as diversity, spatial distribution and architectural complexity of plant communities have been suggested as important determinants of animal assemblages (Lawton 1987). While the direct effect of shrub density on ant species assemblages was not detected in this study, the significant effects of disturbance associated with removal of plant biomass (e.g. logging, fire and grazing) are likely to be highly associated with changes in habitat structure among patches (Gardner et al. 1995). Anthropogenic disturbance is a major driver of ant communities, which is mediated largely through associated habitat structure changes leading to low temperature stress (Hoffman and Andersen 2003). Many ant species are thermophilic (Hölldobler and Wilson 1990) and are likely to be attracted by areas of low plant cover, where there is higher ground insolation. Thus, our finding that bare ground cover influences ant assemblages was unsurprising, although several Melophorus species (MEL; Fig. 4), a recognised Hot Climate Specialist, responded contrary to expectations by reacting negatively to increasing bare ground cover. The positive responses of Monomorium 6 (Generalised Mymicinae) and Rhytidoponera 6 (Opportunist) to less native vegetation cover and greater bare ground supported previous findings that Opportunists and Generalised Myrmicinae prefer more open habitats (Lassau and Hochuli 2004). Notoncus (NOT; Fig. 4) is a Cold Climate Specialist, a group that prefers cooler, more mature forests (Ottonetti et al. 2006). The positive correlation between their abundance and percentage native vegetation cover suggests that Notoncus 7 may be responding to canopy cover at a landscape scale, rather than to local conditions.

The most important habitat predictor of variation in ant species assemblages was clay content of the soil. Clay and sand content is important for the construction of nest mounds for some ant species (Davis-Carter and Sheppard 1993), changes in which can alter nest building activity (de Bruyn 1993). Soil texture and strength may influence differences in community assemblages in semi-arid landscapes (Bestelmeyer and Wiens 2001), and soil structure is likely to have indirect effects on ant composition through changes in vegetation and drainage (Greenslade and Greenslade 1977). Another significant factor in our study 
that has implications for changes in vegetation structure, and hence ant species assemblages, is long-term annual rainfall differences. Long-term rainfall is a major factor influencing woody species recruitment, assuming that density-dependent effects for woody species are relatively weak; indeed, rainfall may have greater effects on woody vegetation structure than management practices such as fire (Fensham et al. 2005). However, not enough information on adult life spans is known to accurately establish the degree to which temporal factors such as rainfall may influence colony persistence.

The principal pattern emerging from species responses to selected environmental predictors was niche separation according to competitive ability. Iridomyrmex spp are members of the Dominant Dolichoderinae that are a competitively superior group of species that co-exist with Hot Climate Specialists (Melophorus spp.) in similar habitats (Andersen 1995; Fig. 4). The observation that competitively inferior Monomorium 6, Pheidole 9 (Generalised Myrmicinae) and Rhytidoponera spp (Opportunists) exhibited very different habitat preferences to Dominant Dolichoderinae and Hot Climate Specialists confirms that competitive ability is an important determinant of ant assemblage composition (Andersen 1995). Functional group analyses indicated that functional groups generally responded to habitat differences based on expected inter-taxa differences in habitat preferences and competitive ability. This is despite the fact that functional group responses to disturbance are seen to be less reliable in arid and semi-arid environments (Hoffmann and Andersen 2003).

The majority of variation in ant assemblages explained by habitat loss, fragmentation and within-patch habitat characteristics represented independent effects of each group. The low proportion of variation that was simultaneously explained by variables belonging to two or more groups was relatively low, suggesting that there was a low number of redundant variables (Cushman and McGarigal 2002). This is expected given the removal of non-significant variables prior to variance partitioning. Nevertheless, it was interesting to note that habitat fragmentation and loss effects were each confounded by within-patch habitat characteristics to a greater extent than localised habitat effects were confounded by landscape structure. For example, our results indicate that $43 \%$ of variation that would be normally considered as independent effects of habitat loss on ant assemblages represents effects that are unable to be distinguished from the effects of fragmentation or local habitat characteristics. The results highlight the disadvantages of quantifying independent landscape structure effects on animal assemblages without also considering localised patch characteristics. The presence of joint effects also emphasises the interrelationships between landscape structure, microclimate and intra-patch vegetation characteristics (Saunders et al. 1991; Didham and Lawton 1999).

The high total variation that remained unexplained by species and functional group models is likely to be largely due to the lack-of-fit of data to the model, and less related to unmeasured explanatory variables or random variation $(\varnothing \mathrm{k}-$ land 1999). Thus, while variance partitioning is a useful method to compare the amount of variation explained by the three groups of predictors, the amount of unexplained variation is less useful as a predictor to determine the degree to which all important variables were captured. Nevertheless, we recognise that other habitat characteristics that were not included in this study may have important influences on ant community structure. For example, the severity of habitat disturbance, fragmentation and habitat loss may only be influential on diversity if it has been sustained sufficiently long for the community to adapt (Mac Nally et al. 2000; Davies et al. 2001). Temporal ecological responses to vegetation change have been largely ignored (Lunt and Spooner 2005), and cannot be accounted for in 'snapshot' studies such as this. Furthermore, species responses to fragmentation and habitat loss can be also confounded by factors such as pre-fragmentation population size, population variability, species mobility (Davies et al. 2000; Tscharntke et al. 2002), grain (Chust et al. 2003) and scale (Andersen 1997; Chust et al. 2003). For the latter, regional effects of fragmentation may override more localised fragmentation processes, but measures of ant abundance and diversity are scaledependent and so cannot be used to determine 
ant assemblage differences among landscapes at larger scales (Andersen 1997).

The species accumulation curve suggests that our sampling may not have detected all ant species present. Sampling for arthropods using pitfall traps is associated with multiple sources of bias (e.g. Spence and Niemelä 1994), since the abundance and richness of species collected is a function of the ability of an individual to be trapped as well as the external community structure. While the 4-day period that the traps remained open has been used to collect ants in Queensland and New South Wales (Jackson and Fox 1996; Vanderwoude 1999), we recognise that the heavy rain that fell while some traps were open may have biased differences in intra-patch assemblages. Another potential source of bias may be differences in habitat structure among patches that may alter ant trappability (Melbourne 1999). However, given the high variety of responses to habitat structure within beetle species (Greenslade 1964), results from Melbourne's (1999) study of temperate grassland ants may not be applicable to Northern Australian semi-arid ant communities.

Lack of knowledge of the relationships between indicator species and ecosystem characteristics is a major obstacle to successfully using indicator species to monitor degradation and recovery in forest ecosystems (Lindenmayer et al. 2000). Ant life histories are not well known, making it difficult to fully understand the viability of ants, particularly at the species level, as bioindicators of habitat condition. However, we believe that this study contributes towards a better understanding of the utility of ants as bioindicators for habitat condition by demonstrating the importance of habitat characteristics, over landscape structure, as drivers of ant assemblages.

Acknowledgements This research was conducted as part of Land and Water Australia Project QNR 28, with financial support from Queensland Department of Natural Resources and Water. We thank landowners for property access and Landcare members for assistance with locating study sites. We thank David Taylor, Scott Swift, Michael Kraus, Melanie Venz, Giselle Whish, Jian Wang, Tonya Hardaker and David Osborne who provided data for this study and we are grateful to Chris Burwell, Rudi Kohout and Alan Andersen for assistance with species identification. We thank Alan Andersen and two anonymous referees for their comments on the manuscript.

\section{Appendix}

Appendix 1 Abundance rating of 116 morphospecies/ species collected in pitfall traps in March and August 2003

\begin{tabular}{|c|c|}
\hline Morphospecies/Species ${ }^{1}$ & Abundance \\
\hline Anochetus rectangularis Mayr & 1.0 \\
\hline Anochetus armstrongi McAreavey & 3.0 \\
\hline Aphaenogaster sp. $1 \mathrm{nr}$. longiceps & 1.6 \\
\hline Calomyrmex sp. 1 & 1.0 \\
\hline Calomyrmex sp. 2 ephippium gp & 1.5 \\
\hline Camponotus sp. 1 & 1.0 \\
\hline Camponotus sp. 3 & 1.0 \\
\hline Camponotus sp. 4 & 1.0 \\
\hline Camponotus sp. 6 aenopilosus gp & 1.0 \\
\hline Camponotus sp. 9 & 1.0 \\
\hline Camponotus sp. 10 & 1.0 \\
\hline Camponotus consobrinus (Erichson) & 1.4 \\
\hline Camponotus loweryi McArthur \& Adams & 1.3 \\
\hline Camponotus sp. 14 & 1.0 \\
\hline Camponotus nigriceps (Smith) & 1.2 \\
\hline Camponotus sp. 19 & 2.0 \\
\hline Camponotus sp. 24 novahollandiae gp & 1.0 \\
\hline Camponotus sp. 25 & 1.0 \\
\hline Camponotus sp. 26 & 1.0 \\
\hline Camponotus sp. 27 & 1.0 \\
\hline Cerapachys sp. 2 brevis gp & 2.0 \\
\hline Cerapachys sp. 3 fervidus gp & 1.0 \\
\hline Crematogaster sp. 1 & 2.5 \\
\hline Crematogaster sp. 2 & 2.6 \\
\hline Crematogaster sp. 3 & 2.1 \\
\hline Crematogaster sp. 4 & 1.0 \\
\hline Crematogaster sp. 5 & 2.2 \\
\hline Crematogaster sp. 6 & 2.4 \\
\hline Crematogaster sp. 7 & 1.8 \\
\hline Iridomyrmex sp. 1 & 3.4 \\
\hline Iridomyrmex sp. 2 rufoniger gp & 3.9 \\
\hline Iridomyrmex purpureus (Smith) & 2.9 \\
\hline Iridomyrmex sp. 4 & 4.0 \\
\hline Iridomyrmex sp. 5 & 4.0 \\
\hline Iridomyrmex sp. 6 & 3.2 \\
\hline Iridomyrmex sp. 7 & 3.2 \\
\hline Leptogenys sp. 1 conigera gp & 1.4 \\
\hline Leptogenys exigua Crawley & 1.0 \\
\hline Melophorus sp. 1 & 2.5 \\
\hline Melophorus sp. 2 & 2.0 \\
\hline Melophorus sp. 3 & 1.6 \\
\hline Melophorus sp. 4 & 2.3 \\
\hline Melophorus sp. 5 & 2.0 \\
\hline Melophorus sp. 6 & 1.3 \\
\hline Melophorus sp. 8 & 1.5 \\
\hline Melophorus sp. 10 & 1.0 \\
\hline Melophorus sp. 11 & 1.1 \\
\hline Melophorus sp. 13 & 2.0 \\
\hline Melophorus sp. 14 & 2.5 \\
\hline Melophorus sp. 18 & 2.0 \\
\hline Meranoplus sp. 1 dimidiatus gp & 1.7 \\
\hline Meranoplus sp. 2 & 1.7 \\
\hline
\end{tabular}


Appendix 1 continued

\begin{tabular}{|c|c|}
\hline Morphospecies/Species ${ }^{1}$ & $\overline{\text { Abundance }}$ \\
\hline Meranoplus puryi Forel & 1.3 \\
\hline Meranoplus sp. 5 gp C sensu Andersen & 1.7 \\
\hline Meranoplus sp. 6 diversus gp & 1.5 \\
\hline Meranoplus sp. 7 diversus gp & 1.4 \\
\hline Meranoplus sp. 8 & 2.0 \\
\hline Meranoplus sp. 9 dimidiatus gp & 2.0 \\
\hline Monomorium sp. 1 nigrius gp & 2.6 \\
\hline Monomorium sp. 2 laeve gp & 3.0 \\
\hline Monomorium sp. 3 carinatum gp & 2.2 \\
\hline Monomorium sculpturatum Clark & 2.6 \\
\hline Monomorium sordidum Forel & 2.7 \\
\hline Monomorium sydneyense Forel & 2.7 \\
\hline Monomorium $\mathrm{sp} .9$ carinatum gp & 2.0 \\
\hline Monomorium rothsteini Forel & 3.0 \\
\hline Monomorium sp. 11 & 2.3 \\
\hline Myrmecia varians Mayr & 1.3 \\
\hline Myrmecia gilberti Forel & 1.0 \\
\hline Myrmecia sp. 5 & 1.0 \\
\hline Notoncus sp. 1 enormis gp & 2.1 \\
\hline Notoncus sp. 2 enormis gp & 2.2 \\
\hline Notoncus ectatommoides (Forel) & 2.4 \\
\hline Notoncus sp. 4 enormis gp & 2.0 \\
\hline Notoncus sp. 6 ectatommoides gp & 2.0 \\
\hline Notoncus sp. 7 ectatommoides gp & 2.4 \\
\hline Odontomachus ruficeps Smith & 1.3 \\
\hline Opisthopsis sp. 1 rufithorax gp & 1.0 \\
\hline Opisthopsis pictus Emery & 1.2 \\
\hline Pachycondyla sp. 1 porcata gp & 1.0 \\
\hline Pachycondyla sp. 4 & 1.0 \\
\hline Papyrius sp. 1 & 3.7 \\
\hline Paratrechina sp.1 & 1.8 \\
\hline Pheidole sp. 1 gp D sensu Andersen & 2.4 \\
\hline Pheidole sp. 3 gp B sensu Andersen & 3.5 \\
\hline Pheidole sp. 4 longiceps gp & 2.3 \\
\hline Pheidole sp. 5 gp E sensu Andersen & 5.0 \\
\hline Pheidole sp. 6 ampla gp & 2.4 \\
\hline Pheidole sp. 7 gp B sensu Andersen & 2.1 \\
\hline Pheidole sp. 8 variabilis gp & 3.0 \\
\hline Pheidole sp. 9 gp E sensu Andersen & 2.1 \\
\hline Podomyrma sp. 1 & 1.0 \\
\hline Polyrachis sidnica Mayr & 2.0 \\
\hline Polyrachis sp. 2 chariomyrma gp & 1.0 \\
\hline Polyrachis schwiedlandi Forel & 1.0 \\
\hline Polyrachis hookeri Lowne & 1.0 \\
\hline Polyrachis sp. 6 chariomyrma gp & 1.0 \\
\hline Polyrachis prometheus Santschi & 1.3 \\
\hline Rhytidoponera sp. 2 & 1.3 \\
\hline Rhytidoponera sp. 3 metallica gp & 1.9 \\
\hline Rhytidoponera convexa (Mayr) & 1.6 \\
\hline Rhytidoponera sp. 5 & 1.0 \\
\hline Rhytidoponera sp. 6 convexa gp & 1.7 \\
\hline Rhytidoponera sp. 8 cristata gp & 1.4 \\
\hline Rhytidoponera sp. 9 & 1.3 \\
\hline Rhytidoponera sp. 10 metallica gp & 1.3 \\
\hline Stigmacros sp. 1 intacta gp & 2.0 \\
\hline Stigmacros sp. 3 aciculata gp & 1.9 \\
\hline
\end{tabular}

Appendix 1 continued

\begin{tabular}{ll}
\hline Morphospecies/Species $^{1}$ & Abundance \\
\hline Stigmacros sp. 5 aemula gp & 2.0 \\
Stigmacros sp. 6 inermis gp & 1.3 \\
Tapinoma sp. 1 & 1.8 \\
Technomyrmex sp. 1 & 2.0 \\
Tetramorium sp. 1 & 1.8 \\
Tetramorium sp. 2 & 2.0 \\
Tetramorium sp. 3 & 2.3 \\
Tetramorium sp. 4 & 2.0
\end{tabular}

${ }_{1}$ Missing species numbers (e.g. Stigmacros sp. 2) represent species that were collected on a preliminary sampling trip prior to 2003

\section{References}

Abensperg-Traun M, Smith GT, Arnold GW et al (1996) The effects of habitat fragmentation and livestockgrazing on animal communities in remnants of gimlet Eucalyptus salubris woodland in the Western Australian wheatbelt. 1. Arthropods. J Appl Ecol 33:12811301

Andersen AN (1995) A classification of Australian ant communities, based on functional groups which parallel plant life forms in relation to stress and disturbance. J Biogeogr 22:15-29

Andersen AN (1997) Using ants as bioindicators: multiscale issues in ant community ecology. In: Conservation Ecology 1:8. http://www.ecologyandsociety.org/ vol1/iss1/art8. Cited 17 December 2004

Andersen AN, Majer JD (2004) Ants show the way Down Under: invertebrates as bioindicators in land management. Front Ecol Environ 2:291-298

Andrén H (1994) Effects of habitat fragmentation on birds and mammals in landscapes with different proportions of suitable habitat: a review. Oikos 71:355-366

Bestelmeyer BT, Wiens JA (2001) Ant biodiversity in semiarid landscape mosaics: the consequences of grazing vs. natural heterogeneity. Ecol Appl 11:1123-1140

Bhar R, Fahrig L (1998) Local vs. landscape effects of woody field borders as barriers to crop pest movement. In: Conservation Ecology 2:3. http://www.ecologyandsociety.org/vol2/iss2/art3. Cited 22 December 2005

Borcard D, Legendre P, Drapeau P (1992) Partialling out the spatial component of ecological variation. Ecology 73:1045-1055

Bowman DMJS, Prior LD (2004) Impact of Aboriginal landscape burning on woody vegetation in Eucalyptus tetrodonta savanna in Arnhem Land, northern Australia. J Biogeogr 31:807-817

Brown JH, Kodric-Brown A (1977) Turnover rates in insular biogeography: effects of immigration on extinction. Ecology 58:445-449 
Chust G, Pretus JL, Ducrot D et al (2003) Identification of landscape units from an insect perspective. Ecography 26: $257-268$

Cushman SA, McGarigal K (2002) Hierarchical, multiscale decomposition of species-environment relationships. Landsc Ecol 17:637-646

Davies KF, Margules CR, Lawrence JF (2000) Which traits of species predict population declines in experimental forest fragments? Ecology 81:1450-1461

Davies KF, Melbourne BA, Margules CR (2001) Effects of within- and between-patch processes on community dynamics in a fragmentation experiment. Ecology 82:1830-1846

Davis-Carter JG, Sheppard DC (1993) Redistribution of metals and nutrients by fire ants in a flue dust contaminated pasture. Soil Biol Biochem 25:747-750

de Bruyn LAL (1993) Ant composition and activity in naturally-vegetated and farmland environments on contrasting soils at Kellerberrin, Western Australia. Soil Biol Biochem 25:1043-1056

Debinski DM, Holt RD (2000) A survey and overview of habitat fragmentation experiments. Cons Biol 14:342355

Didham RK, Lawton JH (1999) Edge structure determines the magnitude of changes in microclimate and vegetation structure in tropical forest fragments. Biotropica 31:17-30

Fahrig L (1997) Relative effects of habitat loss and fragmentation on population extinction. $\mathrm{J}$ Wildl Manage 61:603-610

Fahrig L (2003) Effects of habitat fragmentation on biodiversity. Ann Rev Ecol Evol Syst 34:487-515

Fensham RJ, Fairfax RJ, Archer SR (2005) Rainfall, land use and woody vegetation cover change in semi-arid Australian savanna. J Ecol 93:596-606

Foley P (1997) Extinction models for local populations. In: Hanski IA, Gilpin ME (eds) Metapopulation biology: ecology, genetics and evolution. Academic Press, San Diego

Gardner SM, Cabido MR, Valladares GR et al (1995) The influence of habitat structure on arthropod diversity in Argentine semi-arid Chaco forest. J Veg Sci 6:349-356

Greenslade PJM (1964) Pitfall trapping as a method for studying populations of Carabidae (Coleoptera). J Anim Ecol 33:301-310

Greenslade PJM, Greenslade P (1977) Some effects of vegetation cover and disturbance on tropical ant fauna. Insectes Soc 24:163-182

Greenslade PJM, Halliday RB (1983) Colony dispersion and relationships of meat ants Iridomyrmex purpureus and allies in an arid locality in South Australia. Insectes Soc 30:82-99

Guinto DF, Saffigna PG, Xu Z et al (1999) Soil nitrogen mineralisation and organic matter composition revealed by ${ }^{13} \mathrm{C}$ NMR spectroscopy under repeated prescribed burning in eucalypt forests of south-east Queensland. Aust J Soil Res 37:123-135

Hansen RA (2000) Effects of habitat complexity and composition on a diverse litter microarthropod assemblage. Ecology 81:1120-1132
Hanski I (1999) Metapopulation ecology. Oxford University Press, Oxford

Hobbs R (2001) Synergisms among habitat fragmentation, livestock grazing, and biotic invasions in Southwestern Australia. Cons Biol 15:1522-1528

Hoffmann BD, Andersen AN (2003) Responses of ants to disturbance in Australia, with particular reference to functional groups. Austr Ecol 28:444-464

Hölldobler B, Wilson EO (1990) The ants. SpringerVerlag, Berlin

Jackson GP, Fox BJ (1996) Comparison of regeneration following burning, clearing or mineral sand mining at Tomago, NSW. II. Succession of ant assemblages in a coastal forest. Aust J Ecol 21:200-216

Jellinek S, Driscoll DA, Kirkpatrick JB (2004) Environmental and vegetation variables have a greater influence than habitat fragmentation in structuring lizard communities in remnant urban bushland. Austr Ecol 29:294-304

Jules ES, Shahani P (2003) A broader ecological context to fragmentation: why matrix habitat is more important that we thought. J Veg Sci 14:459-464

Lassau SA, Hochuli DF (2004) Effects of habitat complexity on ant assemblages. Ecography 27:157-164

Laurance WF, Bierregaard RO Jr (eds) (1997) Tropical forest remnants: ecology, management, and conservation of fragmented communities. University of Chicago Press, Chicago

Lawton JH (1987) Are there assembly rules for successional communities In: Gray AJ, Crawley MJ, Edwards PJ (eds) Colonisation, succession and stability. Blackwell Scientific Publications, Oxford

Lindenmayer DB, Margules CR, Botkin D (2000) Indicators of biodiversity for ecologically sustainable forest management. Cons Biol 14:941-950

Lunt ID, Spooner PG (2005) Using historical ecology to understand patterns of biodiversity in fragmented historical landscapes. J Biogeogr 32:1859-1873

MacArthur RH, Wilson EO (1967) The theory of island biogeography. Princeton University Press, Princeton

McGarigal K, Marks BJ (1995) FRAGSTATS: spatial pattern analysis program for quantifying landscape structure. USDA Forest Service, Pacific Northwest Station, GTR-351, Portland

McIntyre S, Barrett GW (1992) Habitat variegation, an alternative to fragmentation. Cons Biol 6:146-147

Mac Nally R, Bennett AF, Horrocks G (2000) Forecasting the impacts of fragmentation. Evaluation of speciesspecific predictions of the impact of habitat fragmentation on birds in the box-ironbark forests of central Victoria, Australia. Biol Conserv 95:7-29

Manly BFJ (1991) Multivariate statistical methods: a primer. Chapman and Hall/CRC, Boca Raton

Martin TG, Green JL (2002) Wildlife and core conservation areas In: McIntyre S, McIvor JG, Heard KM (eds) Managing and conserving grassy woodlands. CSIRO Publishing, Collingwood

Melbourne BA (1999) Bias in the effect of habitat structure on pitfall traps: an experimental evaluation. Aust J Ecol 24: 228-239 
Niemelä J (2001) Carabid beetles (Coleoptera: Carabidae) and habitat fragmentation: a review. Eur J Entomol 98:127-132

$\varnothing$ kland RH (1999) On the variation explained by ordination and constrained ordination axes. J Veg Sci 10: 131-136

Ottonetti L, Tucci L \& Santini G (2006) Recolonization patterns of ants in a rehabilitated lignite mine in central Italy: potential for the use of Mediterranean ants as indicators of restoration processes. Restor Ecol 14: 60-66

Pharo EJ, Lindenmayer DB, Taws N (2004) The effects of large-scale fragmentation on bryophytes in temperate forests. J Appl Ecol 41:910-921

Queensland Department of Natural Resources and Water (2003) Land cover changes in Queensland 1999-2003: a statewide land and tree study report (SLATS). Queensland Department of Natural Resources and Water, Brisbane

Ross KA, Fox BJ, Fox MD (2002) Changes to plant species richness in forest fragments: fragment age, disturbance and fire history may be as important as area. J Biogeogr 29:749-765

Russell-Smith J, Stanton P (2002) Fire regimes and fire management of rainforest communities across northern Australia In: Bradstock RA, Williams JE, Gill, AM (eds) Flammable Australia: the fire regimes and biodiversity of a continent. Cambridge University Press, Cambridge

Samways M, Osborn R, Carliel F (1997) Effect of a highway on ant (Hymenoptera: Formicidae) species composition and abundance, with a recommendation for roadside verge width. Biodivers Conserv 6:903913

Sattler PS, Williams RD (eds) (1999) The conservation status of Queensland's bioregional ecosystems. Environmental Protection Agency, Brisbane

Saunders DA, Hobbs RJ, Margules CR (1991) Biological consequences of ecosystem fragmentation: a review. Cons Biol 5:18-32
Schoereder JH, Sobrinho TG, Ribas CR et al (2004) Colonization and extinction of ant communities in a fragmented landscape. Aust Ecol 29:391-398

Sobrinho TG, Schoereder JH, Sperber C F et al (2003) Does fragmentation alter species composition in ant communities (Hymenoptera: Formicidae)? Sociobiol 42:329-342

Spence JR, Niemelä JK (1994) Sampling carabid assemblages with pitfall traps: the madness and the method. Can Entomol 126: 881-894

Suarez AV, Bolger DT, Case TJ (1998) Effects of fragmentation and invasion on native ant communities in coastal southern California. Ecology 79:20412056

ter Braak CJF, Šmilauer P (2002) CANOCO reference manual and CanoDraw for Windows users guide: software for canonical community ordination. Microcomputer Power, New York

Tews J, Brose U, Grimm V et al (2004) Animal species diversity driven by habitat heterogeneity/diversity: the importance of keystone structures. J Biogeogr 31:79-92

Tscharntke T, Steffan-Dewenter I, Kruess A et al (2002) Characteristics of insect populations on habitat fragments: a mini review. Ecol Res 17:229-239

Vanderwoude C (1999) An evaluation of ant communities as indicators of ecological change resulting from anthropogenic disturbance in spotted gum (Corymbia variegata) forests in south-east Queensland. Dissertation, University of New England

Vanderwoude C, Andersen AN, House APN (1997) Community organization, biogeography and seasonality of ants in an open forest of south-eastern Queensland. Aust J Zool 45:523-537

Wiens JA (1997) Metapopulation dynamics and landscape ecology In: Hanski IA, Gilpin ME (eds) Metapopulation biology: ecology, genetics and evolution. Academic Press, San Diego

Wu J, Shen W, Sun W et al (2002) Empirical patterns of the effects of changing scale on landscape metrics. Landsc Ecol 17:761-782 